$\xi_{p}=$

\title{
Virulence factors and beta-lactamase production among vancomycin-resistant Enterococcus faecalis isolated from clinical samples and hospital environment
}

\author{
Oluwole Moses David ${ }^{1,2 *}$, Kennedy Imonitie ${ }^{1}$, Richard Tope Osuntoyinbo ${ }^{1}$ and Adetunji Kola Olawale ${ }^{3}$ \\ ${ }^{1}$ Department of Microbiology, Ekiti State University, Ado-Ekiti, Ekiti State, Nigeria \\ ${ }^{2}$ Department of Biological Sciences, Joseph Ayo Babalola University, Ikeji-Arakeji, Nigeria \\ ${ }^{3}$ Department of Science Laboratory Science, Osun State Polytechnic, Iree, Nigeria \\ *Corresponding authorE-mail: david.oluwole@eksu.edu.ng
}

\begin{abstract}
Enterococcus faecalis, though opportunistic pathogen has emerged as one of the leading nosocomial pathogens and has been implicated in different human infections. The severity of the infections caused by this organism is largely due to its complex pathogenic process. The objective of this study was to determine the carriage of virulence factors and vanA gene among the strains of vancomycin-resistant $E$. faecalis isolated from hospitals. Standard methods were used for isolation, antibiotic susceptibility and detection of virulence factors in the isolates. A total of one hundred and twenty three (123) samples were screened out of which $69(45.70 \%)$ yielded E. faecalis. The highest percentage of the isolates was recovered from the environment followed by the clinical samples. Children surgical ward had the highest occurrence of the test organism followed by male surgical ward. All the isolates were resistant to both amoxycillin/clavulanic acid and ceftazidime, while $98.55 \%, 89.86 \%$ and $53.62 \%$ were resistant to ampicillin, cefuroxime and gentamicin respectively. Only twenty seven $(39.13 \%)$ of the isolates were resistant to the vancomycin. Among the vancomycin-resistant isolates, haemolysin had the highest occurrence $(60.29 \%)$ followed by caseinase $(55.88 \%)$. A total of $16(59.26 \%)$ were beta-lactamase positive while $8(29.63 \%)$ out of the isolates (vancomycin-resistant) were non-biofilm former while vanA genes was detected in 9 (33.33\%) of the isolates. This study gives an insight to antibiotic resistant pattern of circulating Enterococcus faecalis and also the isolate showed varying patterns of virulent factors.
\end{abstract}

Keywords: Enterococcus Faecalis; Antibiotics; Virulence; Beta-Lactamase; Hospital.

\section{Introduction}

Enterococci are normal microbiota of both vertebrate and invertebrate animals. They belong to the group of lactic acid bacteria and are gram-positive cocci usually in chains that typically survive in harsh environmental conditions (Moellering, 1992). Unlike most bacterial pathogens, they survive in the presence of bile (40\%), temperature $\left(10-45^{\circ} \mathrm{C}\right)$ and sodium chloride $(6.5 \%)$. They also hydrolyse aesculin and pyrrolindonyl-beta-naphthylamide which primarily from the basis of their identification (Noskin, 1997).

Enteroccocci acquires antibiotic resistance with ease and has emerged as the leading nosocomial pathogens. Vancomycin was initially known to be the drug of last resort not until they emerged resistant to it. In the recent time vancomycin, resistance has become a real serious issue in nosocomial infections (Landman et al. 1993). In the hospitals, the transmission of antibiotic-resistant enterococci could be patient-to-patient, environment-to-patients and healthcare workers-to-patients or vice versa. Enterococci has also been reported to have a high survival rate on hands, medical equipment and environmental surfaces (Slaughter et al., 1996).

The current investigation was carried out in selected hospitals in Ekiti State. The objective of the study was to determine the occurrence of vancomycin resistance among Enterococcus faecalis in/on clinical samples, environment and medical equipment. The rate of carriage of virulence factors and vanA gene among the strains of $E$. faecalis that are resistant to vancomycin was determined.

\section{Materials and methods}

\subsection{Collection and processing of samples}

One hundred and twenty three non-repeat samples were collected from various sources: clinical samples, environment sample and medical equipment in five different hospitals in Ekiti States of Nigeria. All experiments were performed in accordance with the international ethical standards. Samples were inoculated on Bile aesculin agar (Oxoid, Basingstoke, UK) and incubated at $35^{\circ} \mathrm{C}$ for 24 - $48 \mathrm{~h}$. Colonies with black halo were sub-cultured to get pure isolates. The isolates were identified by colonial morphology, Gram reactions, motility and oxidase tests. The ability of the isolates to utilize arabinose, inulin, lactose, mannitol, raffinose, sorbitol and sucrose were determined. The results of the isolation were interpreted as described by Holt et al. (1994).

\subsection{Antibiotic susceptibility test}

Enterococcus faecalis strains isolated were standardized by growing at $37{ }^{\circ} \mathrm{C}$ in Mueller-Hinton Broth (Oxoid) for $16 \mathrm{~h}$ and adjusted to an optical density of 0.1 (0.5 McFarland Standard) at a wavelength of $625 \mathrm{~nm}$ spectrophotometrically (UV-VIS 3000PC). The susceptibilities of the isolates to some antibiotics were determined by disc diffusion method as described by Clinical and Laboratory 
Standard Institute (CLSI) (2005). Nine commercial antibiotics (Abtek Biologicals) were tested against the isolates. The concentrations of the commercial antibiotics in microgram are as follows: ampicilin (10), augmentin (30), ceftazidime (30), cefuroxime (30), ciprofloxacin (30), gentamicin (10), nitrofurantoin (300), vancomycin (30) and ofloxacin (5).

\subsection{Detection of $\beta$-lactamase production by iodometric method}

Sodium penicillin $\mathrm{G}$ powder (6 lac units) was dissolved in potassium phosphate buffer $0.05 \mathrm{M}$ (pH 6.0) at a concentration of 6000 $\mu \mathrm{g} / \mathrm{ml}$ (to be prepared fresh when required). Starch solution was prepared by adding $1 \mathrm{gm}$ of soluble starch to $100 \mathrm{ml}$ distilled water and slowly bringing it to boil. Iodine solution was prepared by dissolving $2.03 \mathrm{~g}$ of iodine (BDH) and $53.2 \mathrm{~g}$ of potassium iodide $(\mathrm{BDH})$ in $100 \mathrm{ml}$ distilled water. A $100 \mu \mathrm{l}$ of the penicillin solution was dispensed into a well of microtitre plate. Several pure colonies of the organism were emulsified into the solution to get dense suspension. Two drops of starch were added and then the plate was kept at room temperature for 30-60 minutes. One drop of iodine was then added, which turn the solution blue. The organism in the solution that its blue colour disappeared in 10 minutes was considered as $\beta$-lactamase positive. Negative control with penicillin alone was kept without any culture suspension as described by Bethel and Boonlayengoor (2004).

\subsection{DNA preparation and PCR}

DNA was extraction was done by growing a cells on Mueller Hinton broth overnight and harvested by centrifuging at $13,000 \mathrm{rpm}$ at $10^{\circ} \mathrm{C}$ for 15 minutes. The cells were washed twice in normal saline and $250 \mu \mathrm{l}$ of $10 \mathrm{mM}$ Tris-HCL $(\mathrm{pH} 8)$ and $2.5 \mathrm{mg} / \mathrm{ml}$ of lysozyme was added and the mixture was mixed by vortexing and incubated at $37^{\circ} \mathrm{C}$ for 2 hours. After incubation, $500 \mu 1$ of lysis buffer and $1 \mathrm{mg} / \mathrm{ml}$ of proteinase- $\mathrm{K}$ was added to the cell mixture and incubated at $50^{\circ} \mathrm{C}$ for 1 hour. A $500 \mu l$ of the mixture of phenol:chloroform $(1: 1)$ was added, vortexed and later centrifuged at $13,000 \mathrm{rpm}$ at $4^{\circ} \mathrm{C}$ for 15 minutes. The supernatant was again transferred into another tube and $100 \mu \mathrm{l}$ of $3 \mathrm{M}$ Sodium acetate $(\mathrm{pH} 5.5)$ and $1 \mathrm{ml}$ of absolute ethanol was added and allowed to precipitate overnight on ice. This was followed by centrifugation at 13,000rpm for 30 minutes; the supernatant was decanted away, and the pellets were allowed to dry. After drying, the pellets were dissolved in $50 \mu 1$ of sterile distilled water and stored at $-20^{\circ} \mathrm{C}$.

The presence of vanA genes (with forward vanA5' GGGAAAACGACAATTGC 3' and reverse sequencevanA3'GTACAATGCGGCCGTTA 5') in the isolates were identified by the PCR as describe by Olsvik and Strockbin (1993). A $25 \mu \mathrm{l}$ of PCR amplification mixture contained deionized sterile water, $12.5 \mu 1$ Green Go TaqMaster Mix pH 8 (Promega, USA) contained [(50unit $/ \mathrm{ml})$ of Go TaqDNA polymerase, $(400 \mathrm{Mm})$ of each dNTPs and $(3 \mathrm{mM})$ of $\mathrm{MgCl}_{2}$ ], 1pmol for specific primers (Alpha DNA, Canada). The PCR cycles for the genes were as follow initial denaturation at initial temperature-second $\left(94-120^{\circ} \mathrm{C}\right)$, number of cycles (30), denaturation temperature $54^{\circ} \mathrm{C}$ for 60 seconds, extension temperature of $72^{\circ} \mathrm{C}$ for 60 seconds and the final extension of $72^{\circ} \mathrm{C}$ for 10 mins. using Gradient PCR (TechNet-500, USA). PCR products were electrophoresed on $1.5 \%$ agarose gels in TAE buffer $(40 \mathrm{mM}$ Trisacetate $\mathrm{pH} 8.0 ; 2 \mathrm{mM}$ EDTA). Electrophoresis was performed on horizontal gel and the DNA samples were directly loaded into the gels. Samples were electrophoresed alongside a 100-bp DNA ladder (Sigma-Aldrich). Electrophoresis was performed at a constant voltage $(100 \mathrm{~V})$ until the loading buffer fronts had moved to nearly the end of the gel. After electrophoresis, gels were stained in $0.5 \mathrm{mg} / \mathrm{L}$ ethidium bromide and visualized on a UV transilluminator and the photographs were taken.

\subsection{Determination of virulence factor in Enterococcus faecalis}

\subsubsection{Casein hydrolysis Test}

Isolates were streaked on sterile Mueller-Hinton agar supplemented with $1.5 \%$ skim milk and incubated at $37^{\circ} \mathrm{C}$ for $24 \mathrm{~h}$. Colonies with clear zone after $48 \mathrm{~h}$ was recorded positive for caseinase production as described by Abderrahmen et al. (2014).

\subsection{Detection of gelatine hydrolysis}

The method of Su et al. (1991) was used with a slight modification to detect gelatinase production among the isolates. Briefly, nutrient agar supplemented with $0.4 \%$ by weight, of gelatin (BDH, Merck Chemicals Ltd., Nottingham, England, UK), with a final pH 7.2, was prepared and isolates were streaked on the plates and incubated for $48 \mathrm{~h}$ at $37{ }^{\circ} \mathrm{C}$. The plates were observed for growth and subsequently flooded with $10 \mathrm{ml}$ of a Frazier's solution (mercuric chloride, $15.0 \mathrm{~g}$ in $20 \mathrm{ml}$ of $37 \% \mathrm{v} / \mathrm{v}$ hydrochloric acid, made up to 100 $\mathrm{ml}$ with distilled water). The plates which showed area of opaque layer with zone of clearance around the colonies were taken as positive for gelatin hydrolysis and an uninoculated plate was used as negative control.

\subsection{Haemagglutination test}

The isolates were inoculated into peptone water and concentrated by centrifugation at 3,500 rpm for $10 \mathrm{~min}$ at $4{ }^{\circ} \mathrm{C}$. The bacterial pellet was washed twice in $0.002 \mathrm{M}$ phosphate buffered saline (PBS) (pH 6.8) and re-suspended in $5 \mathrm{ml}$ of the same buffer. Human red blood cells (RBCs) were harvested and washed at 3,000 rpm for 10 min using PBS. The cells were re-suspended in PBS containing $0.1 \%$ ethylene diamine tetraacetic acid (EDTA). Slide haemagglutination tests were carried out by mixing $10 \mu 1$ bacterial suspension (an uninoculated PBS was used as negative control) with $20 \mu \mathrm{l}$ of $2 \%$ harvested human RBCs. The mixture was gently rotated and observed for agglutination within $30 \mathrm{~s}$ according to Gulhan et al. (2006).

\subsection{Detection of haemolysin production}

Brain heart infusion agar (Oxoid) supplemented with 5\% rabbit blood was used for the detection of haemolysin activity. Prepared plates were streaked with the isolates and incubated at $37^{\circ} \mathrm{C}$ for 24 h. After incubation clear zone around the colonies on the plate were recorded to produce beta-haemolysis (Sharma et al., 2007).

\subsection{Biofilm detection assay}

Sterile MHA (Oxoid, Basingstoke. UK) supplemented with $3.0 \%$ $(\mathrm{w} / \mathrm{v})$ sucrose, and $0.08 \%(\mathrm{w} / \mathrm{v})$ congo red dye was inoculated with test organism and incubated at $37^{\circ} \mathrm{C}$ for $24 \mathrm{~h}$. Isolates that produce black colonies were taken to be biofilm producers. Every biofilm forming strains was grown for $18 \mathrm{~h}$ at $37^{\circ} \mathrm{C}$ as pure cultures on Mueller-Hinton broth dispensed into sterile test tubes and diluted to equal 0.5 MacFarland Standard. Each of the standardized organism preparations was incubated at $37^{\circ} \mathrm{C}$ for $24 \mathrm{~h}$. The content of each tube was aspirated and gently rinsed three times with sterile physiological saline. To each of the tubes, $5 \mathrm{ml}$ crystal violet (Fluka) $(0.5 \%)$ solution was added and allowed to stay for $15 \mathrm{~min}$. at room temperature. The tubes were gently rinsed with sterile distilled water three times. Five mililitre of $95 \%$ ethanol were added and the optical density (OD) of each of the content of the tube was measured spectrophotometerically at $520 \mathrm{~nm}$ and the result was interpreted according to Siegfried et al. (1994).

\section{Results and discussion}

Clinical sample (31), environmental (67) and medical equipment (25) were screened in this study. The highest percentage of the isolates was recovered from the environment followed by the clinical samples as shown in Table 1. The medical equipment had the least 
number of the organism. Children surgical ward had the highest occurrence of the test organism followed by male surgical wards. Female medical ward had the least occurrence of E. faecalis. The highest number of enterococci was recovered from the children ward (Table 2).

Antibiotic-resistant Enterococcus spp spread easily especially in the hospital setting. This is due to their intrinsic resistance to both chemical and physical agents. High resistance to antibiotics noted in this study was similar to those reported by Klare et al. (2003), despite the fact that the sources of the isolate were different. The isolates were exposed to nine antibiotics. The susceptibility pattern of the isolates to the different antibiotics varied among the isolates. The report is similar to the report of Busani et al. (2004) that reported higher antibiotic resistance among vancomycin-resistant strains of enterococci from raw meat products, farm animals, and human infections compared to the enterococci vancomycin susceptible ones. All the isolates were resistant to both Amoxycillin/clavulanic acid and ceftazidime, while $98.55 \%, 89.86 \%$ and $53.62 \%$ were resistant to ampicillin, cefuroxime and gentamicin respectively. Twenty seven $(39.13 \%)$ were resistant to vancomycin. Nitrofurantoin was most effective against the isolates (Table 3). Antibiotic resistance could largely be as a result of plasmid transfer from relative organism and also distantly related organisms. Enterococcus faecalis has been reported to have the ability to transfer and receive antibiotic-resistant genes (Andrup and Andersen, 1999). Antibiotic resistance of enterococci associated with human infection has been reported to be very high, and as a result they largely resulted to treatment failure-infections (Dahlen et al. 2000; Kacmaz and Aksoy, 2005).

Table 1: Sources and Frequency of E. faecalis in Clinical Samples, Environment and Medical Equipment

\begin{tabular}{lllll}
\hline Samples & Source & Frequency & Enterococci & E. faecalis \\
\hline \multirow{2}{*}{ Clinical samples } & Wounds & 9 & 13 & $2(15.38)$ \\
& Urine & 22 & 44 & $14(31.82)$ \\
Environment & Bed sheet & 23 & 40 & $16(40.00)$ \\
& Floor & 23 & 36 & $17(47.22)$ \\
& Tables & 21 & 39 & $16(41.03)$ \\
& Statoscopes & 7 & 7 & 0 \\
Medical Equipment & Weighing scale & 5 & 3 & 0 \\
& Couch & 3 & 7 & $1(14.29)$ \\
& Sink & 4 & 3 & 0 \\
Total & Nurses tray & 3 & 5 & $1(20.00)$ \\
& Others & 3 & 151 & $69(45.70)$ \\
\hline
\end{tabular}

\begin{tabular}{lll} 
& Table 2: The Distribution of E. faecalis in Different Ward in the Selected Hospitals \\
\hline Wards & Number screened & Number positive for E. faecalis $(\%)$ \\
\hline Male surgical & 13 & $8(61.54)$ \\
Female medical & 10 & $4(40.00)$ \\
Female surgical & 21 & $12(57.14)$ \\
Children & 44 & $29(65.91)$ \\
Open & 14 & $6(42.86)$ \\
OPD & 21 & $10(47.62)$ \\
Total & 151 & $69(45.70)$ \\
\hline
\end{tabular}

Table 3: Antibiotic Resistant Pattern of E. faecalis Isolated from Hospital

\begin{tabular}{llll}
\hline Antibiotics & Resistance $(\%)$ & Intermediate $(\%)$ & Susceptible (\%) \\
\hline Ceftazidime & $69(100.00)$ & 0 & 0 \\
Cefuroxime & $62(89.86)$ & $3(4.35)$ & $4(5.80)$ \\
Gentamicin & $37(53.62)$ & $7(10.14)$ & $24(34.78)$ \\
Ciprofloxacin & $35(50.72)$ & $17(24.64)$ & $16(23.19)$ \\
Ofloxacin & $26(37.68)$ & $11(15.94)$ & $32(46.38)$ \\
Amoxycillin/clavulanic acid & $69(100.00)$ & 0 & 0 \\
Nitrofurantoin & $20(28.99)$ & $4(5.80)$ & $45(65.22)$ \\
Ampicillin & $68(98.55)$ & $1(1.45)$ & 0 \\
Vancomycin & $27(39.13)$ & $25(36.23)$ & $17(24.64)$ \\
\hline
\end{tabular}

Table 4: The Distribution of Virulence Factors in the Vancomycin-Resistant E. faecalis

\begin{tabular}{lll}
\hline Virulence factors & Frequency & Percentage \\
\hline Caseinase (Cas) & Occurrence & 55.88 \\
Gelatinase (Gel) & 15 & 4.12 \\
Haemaglutinase (Hae) & 12 & 48.53 \\
Haemolysin (Hly) & 13 & 60.29 \\
Cas+Gel & 16 & 20.59 \\
Cas+Hae & 6 & 14.71 \\
Cas+Hly & 4 & 33.82 \\
Gel+Hae & 9 & 20.59 \\
Gel+Hly & 6 & 36.76 \\
Hae+Hly & 10 & 22.06 \\
Cas+Gel+Hae & 6 & 11.76 \\
Cas+Gel+Hly & 3 & 8.82 \\
Gel+Hae+Hly & 2 & 7.35 \\
Cas+Gel+Hae+Hly & 2 & 7.35 \\
\hline
\end{tabular}


Table 5: The Distribution of Beta-Lactamase Production, Biofilm Formation and Van A gene in the Vancomycin-Resistant E. faecalis Isolated from Hospital

\begin{tabular}{llll}
\hline Property & Type & Occurrence & Percentage \\
\hline \multirow{2}{*}{ Beta-lactamase } & Positive & 16 & 59.26 \\
& Negative & 9 & 33.33 \\
Biofilm & None & 8 & 29.63 \\
& Weak & 5 & 18.52 \\
VanA gene & Strong & 14 & 51.85 \\
\hline
\end{tabular}

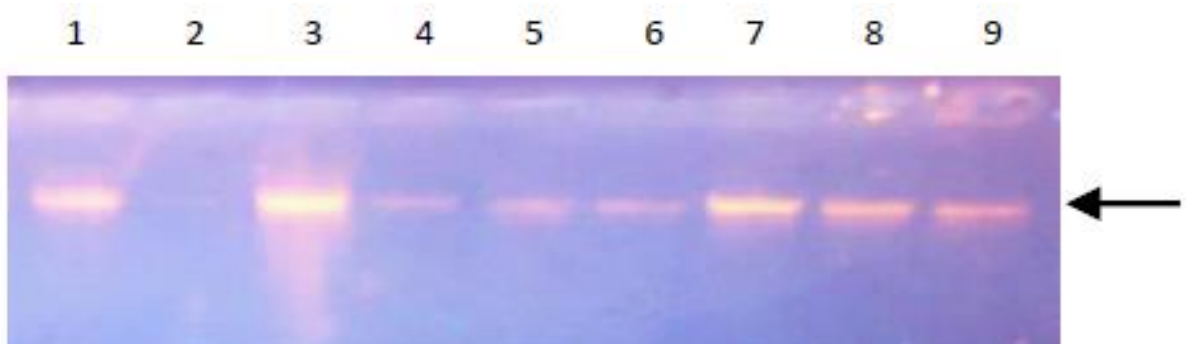

Fig. 1: Agarose gel electrophoresis of PCR products of vanA genes. lane 1 is a molecular weight size marker while lane 2 is negative for vanA gene, lanes 3 to 9 are positive for vanA gene as indicated by $730 \mathrm{bp} \mathrm{PCR} \mathrm{product.}$

Bacterial produces arsenal of virulence factors, this would have been the target of the antimicrobial chemotherapy as stated by Alksne et al. (2000). The presence of four different virulence factors was determined among the isolates. Haemolysin had the highest occurrence $(60.29 \%)$ followed by caseinase $(55.88 \%)$ as shown in Table 4 . Gelatinase $(44.12 \%)$ had the least occurrence in the isolates. The high rate of the virulence factors observed among the vancomycin-resistant is in agreement with the report of Mannu et al. (2003). The incidence of virulence factors and vancomycin-resistant enterococci isolated from hospital is suspected to be higher than those isolated from food samples. The rate of gelatinase production among the vancomycin-resistant strains was lower in this report $(44.12 \%)$ compared to the $65.0 \%$ reported by Comerlato et al. (2013). Gelatinase has been reported to be a prominent virulence factor in enterococci. They take active role in hydrolysis of the gelatin in the host (Lindenstrau et al., 2011) and hence facilitate their spreading.

The presence of multiple antibiotics resistant (in vitro) and multiple virulence factors in the isolates were also determined. Among the isolates that were resistant to vancomycin, $16(59.26 \%)$ were beta-lactamase positive while only $9(33.33 \%)$ did not produce beta-lactamase. Also 8 (29.63\%) of the isolates were non-biofilm former while 5 and 14 were weak and strong biofilm formers as shown in Table 5. The vanA genes was detected in $9(33.33 \%)$ of the isolates (Plate 1). The antimicrobial resistance of E. faecalis should not only be of treatment concern but also virulence of the organism should be considered according to Billstrom et al. (2008) and Kayaoglu and Orstavik (2004).

\section{Conclusion}

This work validate the fact that resistant enterococci are distributed in hospital equipment and the environment of the hospital. The need for improved hygiene and adequate monitoring of the resistance of the pathogens, considering their antibiotic resistance and virulence factors, is recommended. The result of this study could be a good background data in the control and/or management of multiple antibiotic resistant enterococci in the study area.

\section{References}

[1] Abderrahmen M, Nadia L, Abir B, Amina B. Evaluation of the probiotic properties of Bacillus spp. strains isolated from Tunisian hypersaline environments. African Journal of Microbiology Research. 2014; 8 (4):398-405 https://doi.org/10.5897/AJMR2013.5457.

[2] Abderrahmen M, Nadia L, Abir B, Amina B. Evaluation of the probiotic properties of Bacillus spp. strains isolated from Tunisian hypersaline environments. African Journal of Microbiology Research. 2014; 8 (4):398-405 https://doi.org/10.5897/AJMR2013.5457.

[3] Alksne, L. E. and Projan, S. J. (2000). Bacterial virulence as a target for antimicrobial chemotherapy. CurrOpinBiotechnol 11, 625-636. https://doi.org/10.1016/s0958-1669(00)00155-5

[4] Andrup, L. and Andersen, K. (1999). A comparison of the kinetics of plasmid transfer in the conjugation systems encoded by the F plasmid from Escherichia coli and plasmid pCF10 from Enterococcusfaecalis. Microbiology 145, 2001-2009. https://doi.org/10.1099/13500872-145-8-2001.

[5] Bethel CD, Boonlayengoor S. Betalactamase test. In: Clinical microbiology procedures handbook. Isenberg H. D. $2^{\text {nd }}$ Edition. ASM Press. 2004; 1:534-536.

[6] Billström, H., Lund, B., Sullivan, Å. and Nord, C. E.(2008). Virulence and antimicrobial resistance in clinical Enterococcus faecium. International Journal Antimicrobial Agents. 32: 374-377. https://doi.org/10.1016/j.ijantimicag.2008.04.026.

[7] Busani, L., Del Grosso, M., Paladini, C., Graziani, C., Pantosti, A., Biavasco, F. and Caprioli, A. (2004). Antimicrobial susceptibility of vancomycin-susceptible and -resistant enterococci isolated in Italy from raw meat products, farm animals, and human infections. International Journal Food Microbiology 97: 17-22. https://doi.org/10.1016/j.ijfoodmicro.2004.04.008.

[8] CLSI Performance Standards for Antimicrobial Disk Susceptibility Tests; Approved Standard-Eleventh Edition. M02-A11 32(1) Replaces M02-A10. 2012; 29 (1).

[9] Comerlato CB, de Resende MCC, Caierao J, d'Azevedo PA (2013). Presence of virulence factors in Enterococcus faecalis and Enterococcus faeciumsusceptible and resistant to vancomycin. MemInst Oswaldo Cruz. 108(5): 590-595. https://doi.org/10.1590/S007402762013000500009.

[10] Dahlen, G., Samuelsson, W. and Molander, A. (2000). Identification and antimicrobial susceptibility of enterococci isolated from root canal. Oral Microbiollmmunol 15, 309-312. https://doi.org/10.1034/j.1399-302x.2000.150507.x.

[11] Gülhan, T.; Aksakal, A.; Ekin, I.H.; Savașan, S.; and Boynukara, B. 2006. Virulence factors of Enterococcus faeciumand Enterococcus faecalis strains isolated from humans and pets. Turkish Journal of Veterinary and Animal Sciences 30(5): 477-82.

[12] Holt, J. G., Krieg, N. R., Sneath, P. H. A., Staley, J. T. and Williams, S. T. (1994). Bergey's Manual of Determinative Bacteriology 9th Edn. Williams and Wilkins, Baltimore.

[13] Kacmaz, B. and Aksoy, A. (2005). Antimicrobial resistance of enterococci in Turkey. International Journal Antimicrobial Agents 25, 535-538. https://doi.org/10.1016/j.ijantimicag.2005.02.020.

[14] Kayaoglu, G. and Orstavik, D. (2004). Virulence factors of Enterococcus faecalis: relationship to endodontic disease. Crit Rev Oral Biol Med 15, 308-320. https://doi.org/10.1177/154411130401500506.

[15] Klare, I., Konstabel, C., Badstubner, D., Werner, G. and Witte, W. (2003). Occurrence and spread of antibiotic resistances in Enterococcus faecium. International Journal Food Microbiology 88, 269-290. https://doi.org/10.1016/S0168-1605(03)00190-9. 
[16] Landman D, Mobaraki NK, Quale JM. (1993). Novel antibiotic regimens against Enterococcus faeciumresistant to ampicillin, vancomycin, and gentamicin. Antimicrob Agents Chemother. 37:1904-8. https://doi.org/10.1128/AAC.37.9.1904.

[17] Lindenstrau AG, Pavlovic M, Bringmann A, Behr J, Ehrmann MA Vogel RF 2011. Comparison of genotypic and phenotypic cluster analyses of virulence determinants and possible role of CRISPR elements towards their incidence in Enterococcus faecalis and Enterococcus faecium. SystApplMicrobiol 34: 553-560. https://doi.org/10.1016/j.syapm.2011.05.002.

[18] Livornese LL, Dias S, Samuel C, Romanowski B, Taylor S, May P (1992). Hospital-acquired infection with vancomycin resistant Enterococcus faeciumtransmitted by electronic thermometers. Ann Intern Med; 117:112-6. https://doi.org/10.7326/0003-4819-117-2-112.

[19] Lopes, M., Simoes, A. P., Tenreiro, R., Figueiredo Marques, J. J. and Barreto Crespo, M. T. (2006). Activity and expression of a virulence factor, gelatinase, in dairy enterococci. International Journal Food Microbiology 112, 208-214. https://doi.org/10.1016/j.ijfoodmicro.2006.09.004

[20] Mannu, L., Paba, A., Daga, E., Comunian, R., Zanetti, S., Dupre, I. and Sechi, L. A. (2003). Comparison of the incidence of virulence determinants and antibiotic resistance between Enterococcus faecium strains of dairy, animal and clinical origin. International Journal Food Microbiology. 88: 291-304. https://doi.org/10.1016/S0168-1605(03)00191-0.

[21] Moellering RC. Emergence of Enterococcus as a significant pathogen. Clin Infect Dis 1992: 14:1173-8. https://doi.org/10.1093/clinids/14.6.1173.

[22] Noskin, G. A. (1997). Vancomycin-resistant enterococci: Clinical, microbiologic, and epidemiologic features.Journal of Laboratory and Clinical $\quad$ Medicine. $130(1)$ : $14-20$ https://doi.org/10.1016/S0022-2143(97)90054-8.

[23] Sharma S, Bhat GK, Shenoy S. Virulence factors and drug resistance in Escherichia coli isolated from extra-intestinal infections. Indian J Med Microbiol 2007; 25:369-73. https://doi.org/10.4103/02550857.37341.

[24] Siegfried, L., Kmetova, M., Puzová, H., Molokacova, M., Filka J. (1994) Virulence associated factors in Escherichia coli strains isolated from children with urinary tract infections. Journal of Medical Microbiology. 41: 127-132. https://doi.org/10.1099/00222615-41-2127.

[25] Slaughter S, Hayden MK, Nathan C (1996). A comparison of the effect of universal use of gloves and gowns with that of glove use alone on acquisition of vancomycin-resistant enterococci in a medical intensive care unit. Ann. Intern. Med. 215:448-56. https://doi.org/10.7326/0003-4819-125-6-199609150-00004.

[26] Su YA, Sulavik MC, He P, Makinen KK, Makinen PL, Fiedler S, Wirth R, Clewell DB. Nucleotide sequence of the gelatinase gene (gelE) from Enterococcusfaecalis subs. liquefaciens. Infection and Immunity. 1991; 59:415-420. 